\title{
SHORT-TERM OUTCOME IN CHRONIC HEART FAILURE WITH THE ADDITION OF HYDRALAZINE- ISOSORBIDE TO STANDARD ANTI-FAILURE THERAPY- A PROSPECTIVE COMPARISON
}

\author{
Narasimha Pai D', Shiji Thomas 2 , Syed Waleem Pasha ${ }^{3}$, K. Padmanabha Kamath ${ }^{4}$, R. L. Kamath 5 , Chaithra Nayak6, Francis N. P. \\ Monteiro $^{7}$
}

\begin{abstract}
${ }^{1}$ Associate Professor, Department of Cardiology and Interventional Cardiologist, Kasturba Medical College, (Affiliated to MAHE), Mangalore, Karnataka, India.

2Resident, Department of Cardiology, Kasturba Medical College, Mangalore, Karnataka, India

${ }^{3}$ Resident, Department of Cardiology, Kasturba Medical College, Mangalore, Karnataka, India.

${ }^{4}$ Professor and HOD, Department of Cardiology \& Interventional Cardiology, Kasturba Medical College, Mangalore, Karnataka, India.

5 Professor and Former HOD, Department of Cardiology, Kasturba Medical College, Mangalore, Karnataka, India.

${ }^{6}$ Assistant Professor, Department of Cardiology, Kasturba Medical College, Mangalore, Karnataka, India.

${ }^{7}$ Professor, Department of Forensic Medicine and Toxicology, A. J. Institute of Medical Sciences, (Affiliated to Rajiv Gandhi University of Health Sciences), Mangalore, Karnataka, India.
\end{abstract}

ABSTRACT

\section{BACKGROUND}

In spite of improvements in the clinical management of patients with Heart Failure (HF), hospitalisation rates remain high. HF accounts for nearly 3\% of the total healthcare expenditure and these costs are on the rise. We assess the effect of the fixed-dose combination of isosorbide dinitrate and hydralazine on the 60-day all-cause readmission rates in subjects who were discharged alive from their first hospitalisation.

The aim of this study was to see 60 days' outcome of Chronic Heart Failure patients on optimal anti-failure therapy in NYHA III and IV classes on addition of Hydralazine plus Nitrates (H + ISDN) and to compare it with patients without them.

\section{MATERIALS AND METHODS}

This prospective cohort study was undertaken at Department of Cardiology, KMC, Mangalore, affiliated to Manipal University, Manipal. Chronic Heart Failure patients in NYHA class III and IV and patients on conventional Heart Failure therapy including Diuretics and ACE inhibitors were included in this study. The study period extended from 1st May 2015 to 30 th April 2016.

\section{RESULTS}

The mean age of an overall study population was found to be $60.26 \pm 11.41$. Eighty subjects who were on treatment for chronic heart failure were followed up for a period of one month. From the cohort of 80 subjects, patients started on hydralazine plus nitrates formed one arm $(n=40)$ and those who were being managed without them but on conventional anti-failure therapy formed the other arm $(n=40)$. In the hydralazine plus nitrates arm, a significant difference in mean heart rate $(p=0.010)$, JVP $(p<$ $0.001)$, respiratory rate $(p=0.002)$ EDD $(p=0.010)$ and $\operatorname{ESD}(p=0.007)$ was observed on admission and follow-up in one month.

\section{CONCLUSION}

In conclusion, we would recommend $\mathrm{H}+$ ISDN as a promising combianation, since it has shown numerically evident symptom improvement; substantial reduction in 60 days mortality and reduction in hospital readmissions.

\section{KEY WORDS}

Heart Failure; Hospitalisation; Mortality and Treatment.

HOW TO CITE THIS ARTICLE: Pai ND, Thomas S, Pasha SW, et al. Short-term outcome in chronic heart failure with the addition of hydralazine-isosorbide to standard anti-failure therapy- a prospective comparison. J. Evolution Med. Dent. Sci. 2018;7(33):36653669, DOI: $10.14260 /$ jemds/2018/823

\section{BACKGROUND}

In spite of improvements in the clinical management of patients with Heart Failure (HF), hospitalisation rates remain high. ${ }^{1,2} \mathrm{HF}$ accounts for nearly $3 \%$ of the total healthcare expenditure and these costs are on the rise.3,4 Analyses of hospital admissions of patients with symptomatic HF are complicated, because a large number of them die before

'Financial or Other Competing Interest': None.

Submission 03-07-2018, Peer Review 30-07-2018,

Acceptance 06-08-2018, Published 13-08-2018.

Corresponding Author:

Dr. Shiji Thomas,

Department of Cardiology,

Kasturba Medical College,

Mangalore, Karnataka, India.

E-mail: narasimhapai@yahoo.com

DOI: $10.14260 /$ jemds $/ 2018 / 823$

\section{(c) $(1)$}

admission and gives a false interpretation.5,6 So the relationship between hospitalisations and mortality is important when analysing the effects of a treatment for $\mathrm{HF}$ on hospitalisations, especially when the treatment has an effect on the mortality. A composite end point of time to first hospitalisation or death is often used to simplify the analysis of clinical trials. However, the effect of the treatment on hospital admissions is not clear if the treatment affects mortality. Focusing on only the first admission may not represent the treatment's effect on the overall burden of admissions. The risk of death and recurrent admissions are increased after hospital discharge. ${ }^{7}$ Few studies have reported the effect of $\mathrm{HF}$ therapies on all hospitalisations including recurrences. The randomised cardiac resynchronisation trials in comparison of medical therapy, pacing and Defibrillation in Heart Failure (COMPANION) 5 and Multicentre Automatic Defibrillator Implantation Trial with 
Cardiac Resynchronisation Therapy (MADIT-CRT) ${ }^{8}$ were the first HF trials to report a reduction in all hospitalisations for HF using appropriate statistical methods that account for the competing risk of death and correlation of repeated admissions at the same patient. The SHIFT (Systolic Heart Failure Treatment with the IF inhibitor Ivabradine Trial) ${ }^{9}$ and the EMPHASIS-HF (Eplerenone in mild patients with hospitalisation and survival study in heart failure) trials found that the pure heart rate-slowing agent Ivabradine and the mineralocorticoid receptor antagonist eplerenone reduced all HF hospitalisations.

Recently, there has been great interest in reducing allcause readmissions that occur $<30$ days after a hospitalisation for worsening HF.10,11 These data are used to determine Medicare payments to hospitals for inpatient HF care and hospitals with above average readmission rates are being financially penalised. Whether 30-day readmission rates can be reduced by therapy is unclear, and most clinical trials have not reported the effects of treatments on 30-day all-cause readmission rates. Public measures of 30-day readmission rates count all readmissions, not only those for HF. However, most 30-day readmissions are not because of worsening HF and may not be responsive to treatments for HF. ${ }^{10,12}$

Aim of this study is to see 60 days outcome of Chronic Heart Failure patients on optimal anti-failure therapy in NYHA III and IV classes, on addition of Hydralazine plus Nitrates (H+ISDN) and to compare it with patients without them. The objectives of the study are assessment of shortterm mortality as the primary end point; to assess improvement in 6-minute walk test after 60 days of treatment; to evaluate the patient with echocardiography to look for features of LV dysfunction, improvement in parameters over two months' treatment; to examine the patient to evaluate clinical signs of improvement over 60 days; to assess the reduction in hospitalisation within the first two months after initiation of $\mathrm{H}+$ ISDN; and to get a subjective assessment by the patient about symptoms.

\section{MATERIALS AND METHODS}

This prospective cohort study was undertaken at Department of Cardiology, KMC, Mangalore, Affiliated to MAHE, Manipal after the clearance from Institutional Ethics Committee. Chronic Heart Failure patient in NYHA class III and IV and patients on conventional heart failure therapy including Diuretics and ACE inhibitors were included in this study. Patients with other organ failures, acute heart failure, acute coronary syndrome, features of infection, patients with COPD exacerbations, drug defaulters and anaemic patients were excluded from the study. As per inclusion and exclusion criteria, patients with chronic heart failure on follow-up who were started on Hydralazine plus nitrates were assigned to the study and were compared with the same number of patients who were not on hydralazine.

The sample size was decided as per the convenience. Sampling method adopted is purposive sampling. Eighty subjects who were on treatment for chronic heart failure were followed up for a period of two months. From the cohort of 80 subjects, patients started on hydralazine plus nitrates formed one arm $(n=40)$ and those being managed without them but on conventional anti-failure therapy formed the other $\operatorname{arm}(n=40)$.

The study involved short-term outcome of patients after initiation of drug and hence the study period was 60 days. The study period extended from $1^{\text {st }}$ May 2015 to 30th April 2016.

Chronic heart failure patients under the follow-up of all consultants in the Department of Cardiology were assessed for fitness to be included in the study based on the set criteria. Selection of patient to be initiated on H + ISDN was the treating doctor's prerogative and researcher had no role in starting the drugs.

Patients as initiated on hydralazine plus nitrates formed one arm and those who were being managed without them but on conventional anti-failure therapy formed the other arm.

The selection of patients after the consultants have prescribed the drugs were based on the NYHA class of patients in order to avoid bias in sampling. Comparison was done in subgroups of NYHA 3 and 4 with 2 arms.

Patients were evaluated in detail with a questionnaire containing subjective feeling, vital statistics including Heart rate, Blood Pressure, JVP and Respiratory rate were assessed. Patients were assessed, and 6-minute walk was conducted. Echocardiographic evaluation of Systolic and Diastolic function of heart, Chamber size, Ejection fraction and Fractional shortening were assessed and documented. On 60th day of initiation of the drug, patient was reviewed with a repetition of all the above assessment. The data obtained on day 1 and day 60 were documented and analysed.

There were two arms in the study population. Both arms received standard anti-failure treatment including Diuretics, ACE inhibitor/ ARB. Addition of Hydralazine was the primary objective of the study, which was done in half the study number as treated by the primary treating consultant.

Patients were followed up at 60 days. Primary end point was mortality and secondary end points were recurrent hospitalisations and subjective and objective improvement of the symptoms.

The expected outcome was an evidence that showed whether addition of $\mathrm{H}+$ ISDN reduced repeated hospital admissions, improved the heart failure symptoms and signs subjectively as well as objectively.

Data analysis was done by Mean +/- SD in normal distribution of variables and median interquartile ranges if distribution was not normal. Categorical variables were presented as Frequencies or Percentages and Chi-square test was used. Paired T/ Wilcoxon signed rank test was used to find out the difference between pre and post treatment.

\section{RESULTS}

The mean age of an overall study population was found to be $60.26 \pm 11.41$. Table 1 shows the descriptive and clinical characteristics of the study population.

\begin{tabular}{|c|c|}
\hline Variables & Percentage/ Proportion \\
\hline Males & $42(52.5 \%)$ \\
\hline Females & $38(47.5 \%)$ \\
\hline $\begin{array}{c}\text { Presence of Type } 2 \text { Diabetes } \\
\text { Mellitus }\end{array}$ & $42(52.5 \%)$ \\
\hline Presence of Hypertension & $33(41.3 \%)$ \\
\hline
\end{tabular}



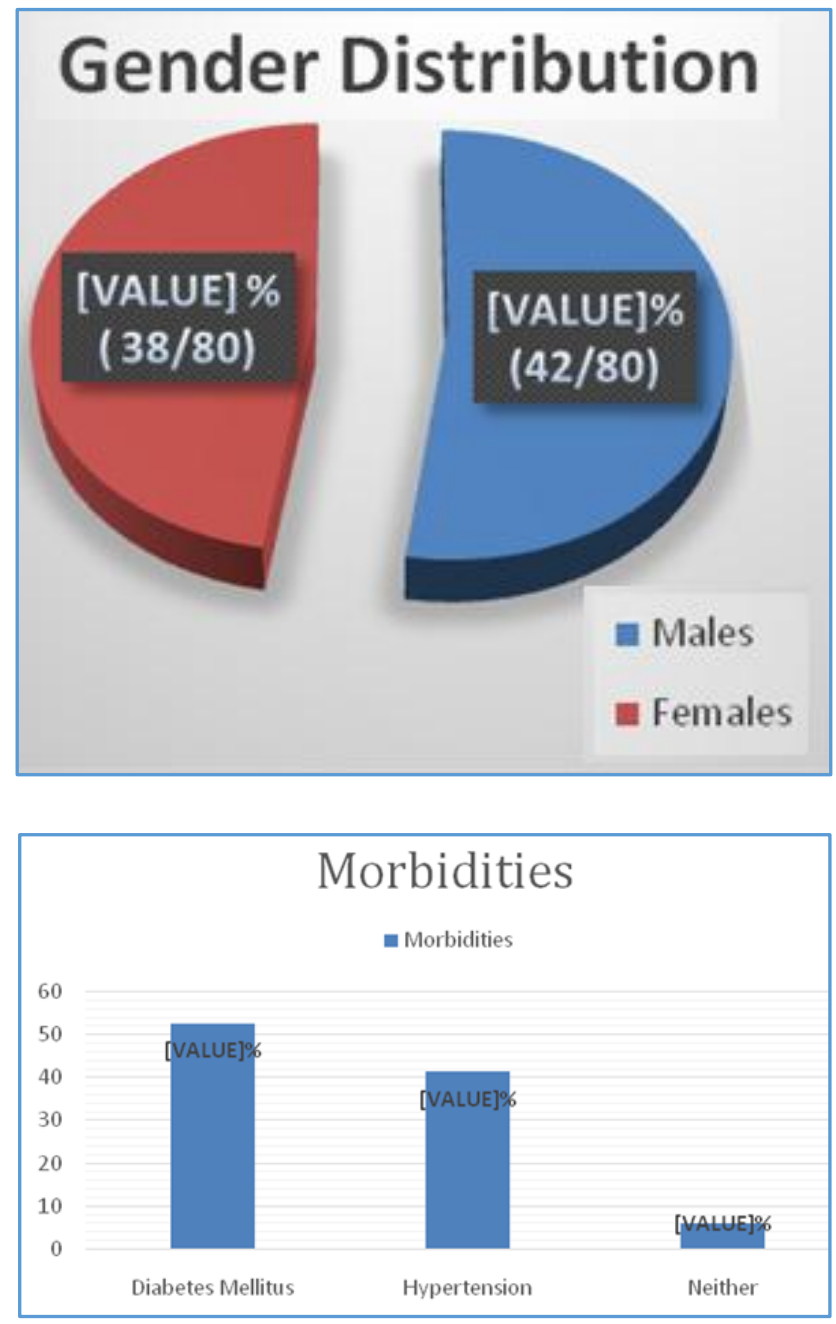

Eighty subjects who were on treatment for chronic heart failure were followed up for a period of one month. From the cohort of 80 subjects, patients started on hydralazine plus nitrates form one arm $(n=40)$ and those managed without them but on conventional anti-failure therapy form the other $\operatorname{arm}(n=40)$.

The primary outcome of the study was to look whether an addition of $\mathrm{H}+$ ISDN reduces the repeated hospital admissions, improves the heart failure symptoms and signs subjectively as well as objectively.

The clinical characteristics of the study population on those with hydralazine plus nitrates at admission and followup at 30 days is as shown in Table 2 .

\begin{tabular}{|c|c|c|c|}
\hline Variables & At Admission & Follow-Up & P value \\
\hline Heart Rate & $96.3 \pm 12.97$ & $81.82 \pm 28.92$ & 0.010 \\
\hline $\begin{array}{l}\text { Systolic Blood } \\
\text { Pressure }\end{array}$ & $134.08 \pm 23.51$ & $132.22 \pm 17.18$ & 0.255 \\
\hline JVP & $2.47 \pm 1.39$ & $1.07 \pm 0.85$ & $<0.001$ \\
\hline Respiratory Rate & $18.85 \pm 3.45$ & $15.4 \pm 5.6$ & 0.002 \\
\hline EDD & $52.27 \pm 4.75$ & $45.3 \pm 6.81$ & 0.010 \\
\hline ESD & $42.22 \pm 4.19$ & $36.4 \pm 3.04$ & 0.007 \\
\hline Ejection Fraction & $33.97 \pm 3.10$ & $32.85 \pm 1.80$ & 0.531 \\
\hline 6 mins walk test & $49.55 \pm 15.66$ & $55.12 \pm 10.27$ & 0.141 \\
\hline \multicolumn{4}{|c|}{$\begin{array}{l}\text { Table 2. Clinical Characteristics of the Study Population on } \\
\text { those with Hydralazine plus Nitrates at Admission and } \\
\text { Follow-Up }(n=40)\end{array}$} \\
\hline
\end{tabular}

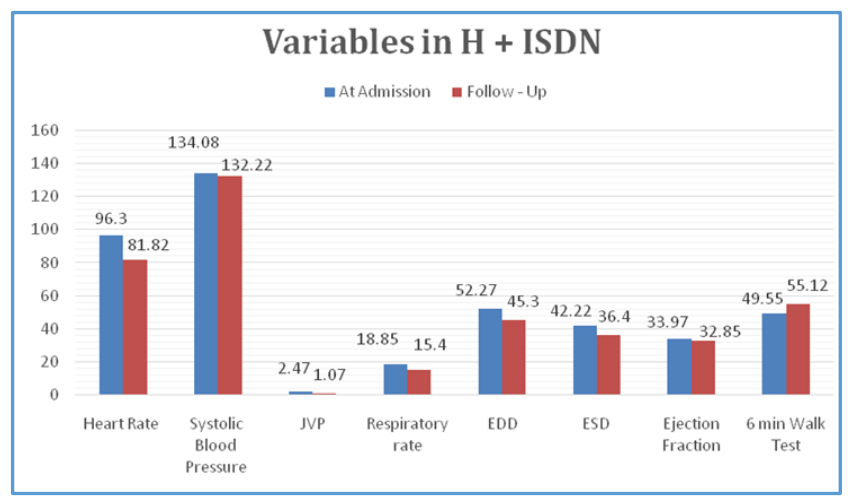

In the hydralazine plus nitrates arm, a significant difference in mean heart rate $(p=0.010)$, JVP $(p<0.001)$, respiratory rate $(\mathrm{p}=0.002)$, EDD $(\mathrm{p}=0.010)$ and $\operatorname{ESD}(\mathrm{p}=$ 0.007) was observed at admission and follow-up at one month. The other variables were not significant (Table 2).

The clinical characteristics of the study population on those with conventional anti-failure therapy at admission and follow-up at 30 days is as shown in Table 3. In conventional anti-failure therapy, a significant difference in mean systolic blood pressure $(p=0.033)$, respiratory rate $(p=0.005)$, EDD $(p=0.008), \operatorname{ESD}(p=0.006)$, ejection fraction $(p=0.010)$ and 6 mins walk test $(p=0.024)$ was observed at admission and follow-up at one month. The other variables were not significant (Table 3).

\begin{tabular}{|c|c|c|c|}
\hline Variables & At Admission & Follow-Up & P value \\
\hline Heart Rate & $91.02 \pm 13.79$ & $85.35 \pm 8.30$ & 0.079 \\
\hline $\begin{array}{c}\text { Systolic Blood } \\
\text { Pressure }\end{array}$ & $124.42 \pm 22.81$ & $121.63 \pm 20.75$ & 0.033 \\
\hline JVP & $2.1 \pm 1.72$ & $1.9 \pm 1.3$ & 0.162 \\
\hline Respiratory Rate & $17.57 \pm 2.5$ & $14.05 \pm 6.9$ & 0.005 \\
\hline EDD & $54.52 \pm 4.64$ & $45.10 \pm 6.41$ & 0.008 \\
\hline ESD & $44.95 \pm 4.97$ & $36.95 \pm 3.87$ & 0.006 \\
\hline Ejection Fraction & $33.32 \pm 2.88$ & $27.72 \pm 3.26$ & 0.010 \\
\hline 6 mins walk test & $49.80 \pm 13.57$ & $41.37 \pm 24.49$ & 0.024 \\
\hline Table 3. Clinical Chactics
\end{tabular}

Table 3. Clinical Characteristics of the Study Population on those with Conventional Anti-Failure Therapy at Admission and Follow-Up $(n=40)$

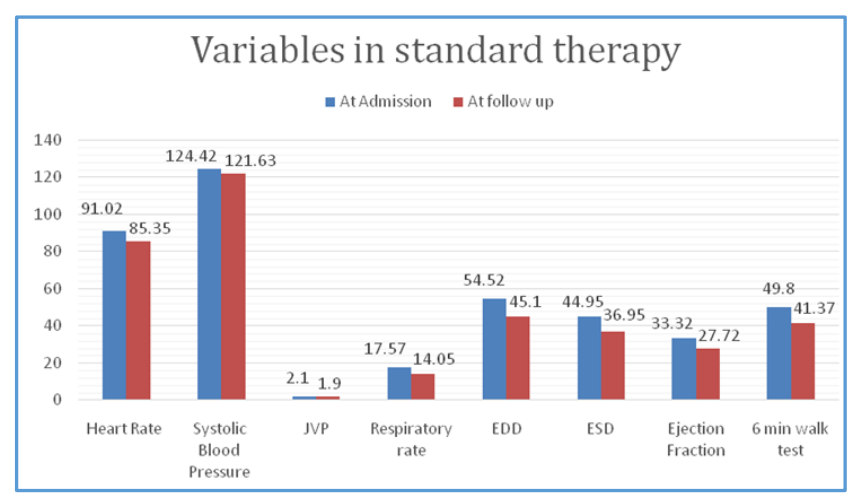

The overall clinical characteristics at admission and follow-up at one month appears to be same in both the arms.

At the end of one month 40 subjects who were on hydralazine plus nitrates $4(10 \%)$ were death, improvement in terms of subjective symptoms and reduced recurrent hospitalisation was seen in $28(70 \%)$ and symptoms were persistent in $8(20 \%)$. 
Among 40 subjects with conventional anti-failure therapy $7(17.50 \%)$ had death, response to treatment was observed in 22 (55\%) and conditions worsened in 11 (27.50\%). A significant improvement in symptoms were observed in both the arms.

Table 4 shows the comparison of outcomes at the end of 30 days in both the arms. A significant improvement in subjective symptoms were observed in subjects who were on hydralazine plus nitrate arm when compared to conventional therapy arm $(p=0.049)$. However, no significant difference was observed when both the arms were compared with respect to other outcome (Table 4).

\begin{tabular}{|c|c|c|c|}
\hline Outcomes & $\begin{array}{c}\text { Hydralazine + } \\
\text { Nitrates } \\
(\mathbf{n = 4 0 )}\end{array}$ & $\begin{array}{c}\text { Conventional } \\
\text { Therapy } \\
\text { (n= 40) }\end{array}$ & P value \\
\hline Death & $4(10 \%)$ & $7(17.5 \%)$ & 0.549 \\
\hline $\begin{array}{c}\text { Reduced } \\
\text { hospitalisation }\end{array}$ & $28(70 \%)$ & $22(55 \%)$ & 0.480 \\
\hline Persistent symptoms & $8(20 \%)$ & $11(27.5 \%)$ & 0.648 \\
\hline $\begin{array}{c}\text { Improvement in } \\
\text { subjective symptoms }\end{array}$ & $29(72.5 \%)$ & $15(37.5 \%)$ & 0.049 \\
\hline $\begin{array}{c}\text { Absence of pedal } \\
\text { oedema }\end{array}$ & $20(50 \%)$ & $11(27.5 \%)$ & 0.159 \\
\hline $\begin{array}{c}\text { Improvement in } \\
\text { NYHA class }\end{array}$ & $29(72.5 \%)$ & $20(50 \%)$ & 0.253 \\
\hline
\end{tabular}

Table 4. Comparison of Outcome at the end of two months in both the Treatment Arms $(n=80)$

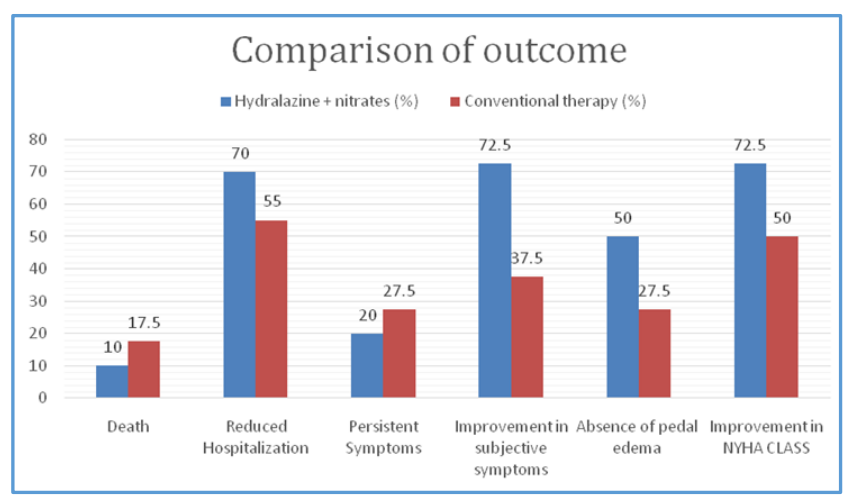

\section{DISCUSSION}

Hydralazine is an arterial vasodilator and nitrates predominantly dilates veins. $\mathrm{H}+$ ISDN combination reduces cardiac preload and after-load due to its combined efficacy as stated.13 The reduction of intracardiac filling pressure helps reduce the adverse cardiac remodeling and hence the benefits in Chronic Heart Failure. Nitrates enhances nitric oxide bioavailability, since they serve as nitric oxide donors and hydralazine is an antioxidant that reduces consumption of nitric oxide. This synergistic action of two molecules add to the cumulative benefit of $\mathrm{H}$-ISDN in chronic heart failure.

A-HeFT, V-HeFT 1 and V-HeFT 2 have evaluated the benefits of $\mathrm{H}+$ ISDN in various groups and in different comparisons. The net result showed a favourable outcome in AfricanAmericans with Chronic Heart Failure NYHA III and IV symptoms, who were already on standard anti-failure therapy. ${ }^{14,15}$

This has prompted us to conduct a research on Indian population with same symptomatology, the effect of $\mathrm{H}+$ ISDN, but with certain different parameters. All previous studies were carried out in select populations over a period of two to three years. However, it is told that the study was terminated early because of the evident benefits on $\mathrm{H}+$ ISDN arm over the other group. Hence, our study was to focus on the short term, which was set in as 60 days, benefit of the patient group who were given H+ISDN to their existing antifailure medicines. We randomised our patients into 2 groups. One arm continued the same maintenance anti-failure drugs. The other arm received combination of H-ISDN atop their regular cardiac drugs. All the patients were followed up as planned in the protocols including Echocardiography, 6minutes walk test and symptom charting.

The cross-section of patients in our study includes patients from southern states of India who were under regular follow-up of 6 interventional cardiologists of our Institution. Patients were randomly selected from the Outpatient and Inpatient departments and the choice was random, not influenced by either consultants or the researcher. The choice of addition of $\mathrm{H}+$ ISDN to ongoing therapy was vested with the primary physicians who had given permission to conduct research, who otherwise did not interfere with study till final analysis.

The aim of the research was to see the reduction in mortality at the end of 2 months in either arm compared to the other. Other aims were to assess whether addition of $\mathrm{H}$ ISDN reduces hospitalisation in the short period of 2 months after initiation of drugs. 6 minutes walk test was the standard we followed to assess objective improvement, on top of the ECHO evaluation of LV function improvement.

The commonest conditions causing Heart Failure with reduced Ejection Fraction, except Valvular Heart Disease and Congenital Heart Diseases, were considered for our research, which included Ischaemic Heart Disease, Ischaemic Cardiomyopathy, Hypertensive heart disease. Dilated cardiomyopathy, Tachycardiomyopathy and Peripartum cardiomyopathy were considered to be included. But we could not include them in the current study, due to nonrepresentation and unwillingness of patients.

Following AHA/ ACC guidelines, which gives class 1A indication for H-ISDN to be started in NYHA III and IV, we opted to study only on the said group of patients with prespecified exclusion criteria. All our patients were diagnosed to have chronic heart failure and were under the follow-up of the Cardiology Department of our institution. Choice of patients were not influenced by any bias, neither was the arm to which they were recruited.

\section{Limitations}

1. Our study was done at a single centre with predominantly south Indian population as subject group.

2. Sample size is statistically sufficient, but a higher number might disclose a wide variation in response as evidenced by the person-to-person variations noted in our study, whereby incorporating various forms of heart failures as proposed in study which could not be fulfilled due to non-representation and unwillingness of available patients to join the study.

3. Our study was a prospective comparison of two arms, whereas a randomised double-blind study will elucidate much more dependable results.

4. LV function would have been more accurate had we applied strain and strain rate assessment in echo, which could not be carried out mainly due to unwillingness of patients to undergo time consuming studies. 
5. Newer molecules like ARB + Neprilysin Inhibitor Sacubitril has come up with significant margin of benefit in heart failure therapy in several trials, and hence the future of H-ISDN as an add-on therapy is challenging.

\section{CONCLUSION}

1. $\mathrm{H}+$ ISDN, a class I indication for heart failure, as specified by ACC/ AHA is beneficial to heart failure patients not only in the long-term, but also in the short 60 days period as proved in our study in a cross-section of Indian patients in NYHA class 3 and 4, though we could not prove the statistical significance, may be due to several confounding factors as mentioned in the limitations below.

2. At the end of one month, 40 subjects who were on hydralazine plus nitrates, $4 \quad(10 \%)$ were dead, improvement in terms of subjective symptoms and reduced recurrent hospitalisation was seen in $28(70 \%)$ and symptoms were persistent in 8 (20\%).

3. Among 40 subjects with conventional anti-failure therapy, $7(17.50 \%)$ had death, response to treatment was observed in 22 (55\%) and conditions worsened in $11(27.50 \%)$. A significant improvement in symptoms were observed in both the arms.

4. A significant improvement in subjective symptoms were observed in subjects who were on hydralazine plus nitrate arm when compared to conventional therapy arm $(p=0.049)$. However, no statistically significant difference was observed when both the arms were compared with respect to other outcome.

5. In conclusion, we would recommend $\mathrm{H}+$ ISDN as a promising combination, since it has shown-

a. Numerically evident symptom improvement.

b. Substantial reduction in 60 days mortality.

c. Reduction in hospital readmissions.

d. Improvement in Echo results, 6 mins walk test, though not significant statistically.

A detailed multicentre study adding the missed causes of heart failure in our studies with incorporation of newer echo techniques like speckle tracking, strain and strain rate assessment will bring about the true potential of the said combination.

\section{REFERENCES}

[1] Jha AK, Orav EJ, Epstein AM. Public reporting of discharge planning and rates of readmissions. N Engl J Med 2009;361(27):2637-45.

[2] Dunlay SM, Redfield MM, Weston SA, et al. Hospitalizations after heart failure diagnosis a community perspective. J Am Coll Cardiol 2009;54(18):1695-702.
[3] Jencks SF, Williams MV, Coleman EA. Rehospitalizations among patients in the Medicare fee-for-service program. $\mathrm{N}$ Engl $\mathrm{J}$ Med 2009;360(14):1418-28.

[4] Joynt KE, Orav EJ, Jha AK. Thirty-day readmission rates for Medicare beneficiaries by race and site of care. JAMA 2011;305(7):675-81.

[5] Anand IS, Carson P, Galle E, et al. Cardiac resynchronization therapy reduces the risk of hospitalizations in patients with advanced heart failure: results from the Comparison of Medical Therapy, Pacing and Defibrillation in Heart Failure (COMPANION) trial. Circulation 2009;119(7):969-77.

[6] Rogers JK, McMurray JJ, Pocock SJ, et al. Eplerenone in patients with systolic heart failure and mild symptoms: analysis of repeat hospitalizations. Circulation 2012;126(19):2317-23.

[7] Solomon SD, Dobson J, Pocock S, et al. Influence of nonfatal hospitalization for heart failure on subsequent mortality in patients with chronic heart failure. Circulation 2007;116(13):1482-7.

[8] Goldenberg I, Hall WJ, Beck CA, et al. Reduction of the risk of recurring heart failure events with cardiac resynchronization therapy: MADIT-CRT (Multicenter Automatic Defibrillator Implantation Trial With Cardiac Resynchronization Therapy). J Am Coll Cardiol 2011;58(7):729-37.

[9] Borer JS, Böhm M, Ford I, et al. Effect of ivabradine on recurrent hospitalization for worsening heart failure in patients with chronic systolic heart failure: the SHIFT Study. Eur Heart J 2012;33(22):2813-20.

[10] Dharmarajan K, Hsieh AF, Lin Z, et al. Diagnoses and timing of 30-day readmissions after hospitalization for heart failure, acute myocardial infarction or pneumonia. JAMA 2013;309(4):355-63.

[11] Vaduganathan M, Bonow RO, Gheorghiade M. Thirtyday readmissions: the clock is ticking. JAMA 2013;309(4):345-6.

[12] Gheorghiade M, Vaduganathan M, Fonarow GC, et al. Rehospitalization for heart failure: problems and perspectives. J Am Coll Cardiol 2013;61(4):391-403.

[13] Pierpont GL, Cohn JN, Franciosa JA. Combined oral hydralazine-nitrate therapy in left ventricular failure: hemodynamic equivalency to sodium nitroprusside. Chest 1978;73(1):8-13.

[14] Franciosa JA, Pierpont G, Cohn JN. Hemodynamic improvement after oral hydralazine in left ventricular failure: a comparison with nitroprusside infusion in 16 patients. Ann Intern Med 1977;86(4):388-93.

[15] Cohn JN, Archibald DG, Ziesche S, et al. Effect of vasodilator therapy on mortality in chronic congestive heart failure: results of a Veterans Administration Cooperative Study. N Engl J Med 1986;314(24):154752. 